Efficiency depends on whether a drug is worth its cost to individuals or society. The most efficacious treatment, based on the best evidence, may not be the most cost-effective option. It may not be acceptable to patients. In every country, rationing of health care is a reality. There is no country, however wealthy, that can afford to deliver all the health care possible to the whole of its population at all times. Rationing may be implicit or explicit, but it will happen. Good effectiveness and efficiency studies will make this rationing more informed.

Good practical guidelines, such as the Therapeutic Guidelines series, are clearly very important and extremely useful. They could be made even more relevant to the patient in front of the doctor, by being less dependent on efficacy studies. We should make more use of effectiveness and efficiency studies and abandon the censorship of the evidence drawn from them.

\author{
REFERENCES \\ 1. Haynes B. Can it work? Does it work? Is it worth it? Br Med J 1999;319: \\ 652-3. \\ 2. Greenhalgh T. Is my practice evidence-based? Br Med J 1996;313:957-8.
}

E-mail: john.marley@medicine.adelaide.edu.au

\title{
Letters
}

Letters, which may not necessarily be published in full, should be restricted to not more than 250 words. When relevant, comment on the letter is sought from the author. Due to production schedules, it is normally not possible to publish letters received in response to material appearing in a particular issue earlier than the second or third subsequent issue.

\section{Prescribing by numbers}

Editor, - It was interesting to see an article on the number needed to treat (NNT) (Aust Prescr 2000;23:38). NNT is better than looking at relative risk reductions but NNT still does not always give you a feel for the relevance of an intervention.

I believe clinical decision-making needs to consider two numbers. These are the paired absolute incidences.

$\mathrm{X}=$ Event rate control (the outcome with placebo, or the outcome if you do nothing)

$\mathrm{Y}=$ Event rate active (the outcome with treatment)

Consider a room full of 100 people with a clinical problem. Put it to them, 'Do nothing and the event will happen to $\mathrm{X}$ of you, and if all of you take the pill it will happen to Y of you.' Using the Helsinki Heart study as quoted in the article, how would 100 men respond if told 'Take gemfibrozil for five years and 4.1 of you will have an event, do nothing and 2.7 of you will have an event'? I suspect many would say why bother with treatment, but some would say OK.

Clinical decision-making needs to be made in the context of real people. Other comorbidity, patient attitude, patient expectations, the psychological burden of disease label, adverse effects, secondary costs (for example, more visits to the doctor) all need consideration. I believe that by looking at the two numbers ( $\mathrm{X}$ and $\mathrm{Y}$ ) I can get a better feel for the relevance of an intervention, and also inform my patients about 'doing something' versus 'doing nothing'.

I believe the treatment of risk and risk factors is greatly overrated, and that many are treated for risk without a genuine consideration of how much of a difference it could make for the individual. As the surgeons learn to withhold the knife, I believe we should learn to hold back the drug treatment of risk factors, not because there is no evidence, but because in the bigger picture it is irrelevant to the patient this will be facilitated by looking at the $\mathrm{X}$ and $\mathrm{Y}$ numbers.

Paul Neeskens

General Practitioner

Hervey Bay, Qld

\section{Medicines and the media}

Editor, - The Australian Prescriber editorial (Aust Prescr 2000;23:70-1) regarding reporting of medicines in the media is timely. On 13 April 2000, an article in the Adelaide 'Advertiser' included the headline 'Accepted safe levels of cholesterol "still too high", and pictured a young woman having a cholesterol test. The commentary continued, 'Worldwide evidence proved "normal" cholesterol levels in healthy men and women were too high, an international authority on heart disease said in Adelaide yesterday'. The article went on to talk about '...a new ultra-low dose cholesterol-reducing drug called cerivastatin, ...recently approved for use in Australia...'

Assuming a new study had been released assessing health outcomes associated with cerivastatin, we contacted the reporter. He could not provide any information to support the story, but suggested we contact the Adelaide marketing company publicising the visit of the overseas specialist. The marketing company supplied their media release, but could not provide a reference. They reported the media release was redrafted from one produced by a Sydney company. The Sydney marketing company also could not provide a reference. They said their media release was based on information supplied by Bayer, but they had returned all material to Bayer.

We rang Bayer on five occasions. The product manager was never available to speak to us, nor has he returned our call. The Adelaide marketing company, however, was more sympathetic. They rang us back to say the West of Scotland Coronary Prevention Study, a 1995 study involving pravastatin, was the basis for the story. Was the story 'news' or advertising? How can consumers tell the difference?

Libby Roughead and

Andrew Gilbert

School of Pharmacy and Medical Sciences

University of South Australia

Adelaide 


\section{Paracetamol in childhood fever}

Editor, - I am writing about the use of paracetamol and non-steroidal anti-inflammatory drugs (NSAIDs) ('Paracetamol: overused in childhood fever' Aust Prescr 2000;23:60-1). For a while we have been bogged down with the controversy about the concurrent prescribing of paracetamol and ibuprofen to children who have fever which is not controlled by paracetamol alone.

The current practice here is not to give paracetamol fourhourly for more than one day, after which the patient is advised to switch to six-hourly. As such, if breakthrough fever occurs after one day on paracetamol, some doctors advise patients to stagger the paracetamol dose with ibuprofen three hours inbetween.

What would be the concern about nephrotoxicity/ hepatotoxicity when giving the two preparations concurrently to children?

\section{Hing Wee Chuan}

Drug Information Pharmacist

KK Hospital

Singapore

Professor Ric Day and Dr Robert Graham, St Vincent's Hospital, Sydney, and Dr Noel Cranswick, Royal Children's Hospital, Melbourne, comment:

Mr Hing Wee Chuan enquires about the use of paracetamol in combination with ibuprofen in children whose pyrexia does not respond to paracetamol alone. Firstly, the question should be asked whether the temperature needs to be lowered at all. There is increasing evidence ${ }^{1}$ that routine fever reduction is unnecessary, with no evidence that the risk of febrile seizures is reduced ${ }^{2}$ and some viral illnesses may even be prolonged. ${ }^{3}$

Prolonged dosing of paracetamol needs to be kept below $60 \mathrm{mg} / \mathrm{kg} / \mathrm{day}$ in children to minimise the risk of liver toxicity. The practice of dosing four-hourly on day 1 and six-hourly thereafter as is practised in Mr Hing's hospital is acceptable as long as the daily dose limits are not exceeded. However, there is no evidence that the practice has any safety advantage. A clear upper limit for ibuprofen dosage in children for antipyresis has not been established. However, some adverse effects may be dose related. Uncommon but potentially serious adverse effects include aspirin-like sensitivity, renal toxicity and gastrointestinal bleeding.

If it is decided to treat fever, there is no evidence that the combination of paracetamol and ibuprofen is more effective than either drug alone. However, there is evidence from adult studies that the dose of NSAIDs can be reduced without loss of analgesic efficacy when paracetamol is used concomitantly. ${ }^{4}$ In this study there were fewer minor adverse effects such as dyspepsia when naproxen was combined with paracetamol in the treatment of rheumatoid arthritis, probably related to the lower dose of NSAID employed in the combination regimen. There is a safety benefit in combining NSAIDs with paracetamol if the dose of NSAID used is less than would normally be the case. We know that the risk of serious upper gastrointestinal adverse reactions to NSAIDs increases with the dose rate of NSAID. ${ }^{5}$ This would be most pertinent in those at increased risk, particularly the elderly. Ibuprofen, like all NSAIDs, can be hazardous in patients with hepatic or renal impairment or in hypovolaemic situations. ${ }^{6}$ Paracetamol in this context could theoretically increase the risk of further hepatic damage.

Whether there is any merit in using the combination to treat fever would need to be subject to controlled studies. In the interim, there seems little evidence either to support or to raise concerns about the practice.

\section{REFERENCES}

1. Kramer MS, Naimark LE, Roberts-Brauer R, McDougall A, Leduc DG. Risks and benefits of paracetamol antipyresis in young children with fever of presumed viral origin. Lancet 1991;337:591-4.

2. Schnaiderman D, Lahat E, Sheefer T, Aladjem M. Antipyretic effectiveness of acetaminophen in febrile seizures: ongoing prophylaxis versus sporadic usage. Eur J Pediatr 1993;152:747-9.

3. Graham NMH, Burrell CJ, Douglas RM, Debelle P, Davies L. Adverse effects of aspirin, acetaminophen and ibuprofen on immune function, viral shedding, and clinical status in rhinovirus-infected volunteers. J Infect Dis 1990;162:1277-82.

4. Seideman P, Melander A. Equianalgesic effects of paracetamol and indomethacin in rheumatoid arthritis. Br J Rheumatol 1988;27:117-22.

5. Simon LS. Risk factors and current NSAID use [editorial]. J Rheumatol 1999;26:1429-31.

6. Johnson AG, Day RO. The problems and pitfalls of NSAID therapy in the elderly (Parts I \& II). Drugs Aging 1991;1:130-43, 212-27.

\section{Treating acute sinusitis}

Editor, - In the article 'Treating acute sinusitis' (Aust Prescr 2000;23:39-41), the author stated that 'patients allergic to penicillin should be treated with either trimethoprimsulfamethoxazole or cefaclor'. Because cefaclor is a cephalosporin, the statement raises questions about crosssensitivity with penicillins.

In my experience, substantial numbers of clinicians are still confused about the possibility of cross-sensitivity between various beta-lactam antibiotics. I think this topic deserves clarification.

It is well known that cephalosporins might show crosssensitivity with penicillins. The frequency of cross-reactions is uncertain, but is probably relatively low, around $5-10 \%$ (in immunological studies up to 20\%). It seems that the patients with a history of mild reactions to penicillins are at low risk of developing an allergic reaction following administration of a cephalosporin. On the other hand, many authorities recommend that if a patient has ever experienced a severe allergic reaction (anaphylaxis) to penicillin, it is strongly advisable not to give a cephalosporin.

\section{Dragan Milovanovic}

Pharmacologist and Clinical Pharmacologist in Training Department of Phamacology, Medical Faculty

and

Center for Clinical and Experimental Pharmacology

Clinical Hospital Centre

Kragujevac

FR Yugoslavia 


\section{Management of hypertension}

Editor, - The National Heart Foundation of Australia released its 1999 Guide to Management of Hypertension for Doctors in October last year. ${ }^{1}$ Since then a large outcome study (ALLHAT) in the USA has demonstrated that antihypertensive therapy with the alpha blocker doxazosin is associated with more cardiovascular events and a greater chance of patients being hospitalised for congestive heart failure than therapy with a regimen based on a thiazide diuretic. ${ }^{2}$ As a result of this study, the National Heart Foundation does not recommend that alpha blockers be considered as an option in the first-line management of hypertension.

This recommendation does not preclude considering alpha blockers as additional drugs, after initiation with a first-line drug, if combination therapy is required to achieve good blood pressure control.
Although alpha blockers may still be used for symptom relief in patients with prostatism without manifest or suspected heart failure, the ALLHAT results suggest that, if the person is also hypertensive, their outcome will not be as good as if they were treated with a regimen based on a thiazide diuretic. It is also likely that they will have a higher chance of being admitted to hospital with heart failure.

Professor Lindon Wing

Chair and members

National Blood Pressure Advisory Committee

National Heart Foundation

Melbourne

REFERENCES

1. 1999 Guide to management of hypertension for doctors. Sydney: National Heart Foundation of Australia; 1999.

2. ALLHAT Collaborative Research Group. Major cardiovascular events in hypertensive patients randomized to doxazosin vs chlorthalidone: the antihypertensive and lipid-lowering treatment to prevent heart attack trial (ALLHAT). JAMA 2000;283:1967-75.

\section{Volume 1 Number 1}

It was twenty-five years ago that the first issue of Australian Prescriber was published.

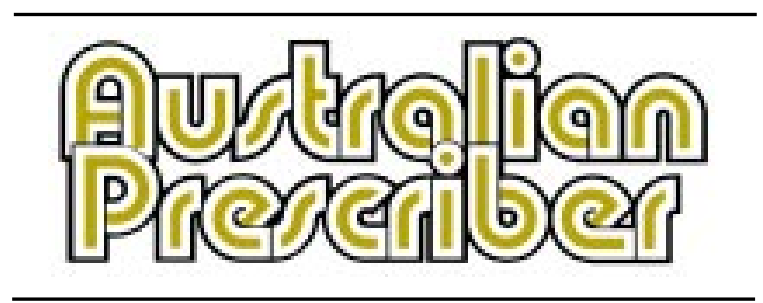

Volume 1 Number 1 of October/December 1975 carried an editorial on the journal's launch and its purpose. The Editorial Board had six members, the Advisory Editorial Panel thirty member societies. Contents of this first issue were:

Lofty, but attainable, aims? The prescriber's pen (and pad) is mightier than the sword (scalpel).

The use of diuretics in the treatment of hypertension Certain diuretics remain the initial treatment of choice in most patients with hypertension. The article includes some analysis of cost and prescription volume.

Phenytoin plasma levels: the measurement of plasma levels of antiepileptic drugs - Modern techniques may improve management of a common condition.

Mazindol (anorectic) - The first of a series of monographs on new drugs, including comparative costs of five anorectics.

Adverse drug reactions - The Adverse Drug Reactions Bulletin was incorporated in Australian Prescriber. Six topics are reported on, including deafness and chlorhexidine drops, and oral contraceptives and the eye.

Nocturnal cramps - A common complaint with no single treatment.
The treatment of enuresis in childhood - The article was reproduced from the UK Prescriber's Journal, with comment by two Australian consultants.

Quiz - your diagnosis, doctor?

Should diazepam be used in epilepsy? - A paper suggesting that only intravenous diazepam has a place.

Metric only in 'Prescriber' - The medical profession is familiar with most metric units. It will be the policy of Australian Prescriber to use SI units.

Book review: 'Medical Nemesis' - The reviewer discovers some 'rays of truth' in Ivan Illich's critique of the 'medicalisation' of industrial society, and clinical iatrogenesis.

Theriac - an old-time panacea.

An accompanying letter from the then Minister for Health stated that Australian Prescriber aimed to meet the need for 'balanced, impartial, reliable, up-to-date information on therapy and preventive patient care'.

He said, 'The Department of Health has a clear responsibility to provide information and to ventilate informed opinions on which practitioners may confidently base the critical decisions they are called on to make daily. The journal will aim to indicate to the practitioner the part, large or small, played by drugs in the treatment of any given condition.'

Twenty-five years later the journal is still expanding its audience thanks to the internet. It has grown to six issues per year, and continues to publish critical reviews of the drugs Australian doctors prescribe for their patients.

Look at the Gallery of past Australian Prescriber covers on the internet home page (www.australianprescriber.com) for a colourful display of covers since the seventies. 